\title{
Molecular Imaging to Track Parkinson's Disease and Atypical Parkinsonisms: New Imaging Frontiers
}

Antonio P. Strafella, MD PhD, ${ }^{1 *}$ Nicolaas I. Bohnen, MD, ${ }^{2}$ Joel S. Perlmutter, MD, ${ }^{3}$ David Eidelberg, MD, ${ }^{4}$ Nicola Pavese, MD, ${ }^{5}$ Thilo Van Eimeren, MD, ${ }^{6}$ Paola Piccini, MD, ${ }^{7}$ Marios Politis, MD, ${ }^{8}$ Stephane Thobois, MD, ${ }^{9}$ Roberto Ceravolo, MD, ${ }^{10}$ Makoto Higuchi, MD, ${ }^{11}$ Valtteri Kaasinen, MD, ${ }^{12}$ Mario Masellis, MD, PhD, ${ }^{13} \mathrm{M}$. Cecilia Peralta, MD, ${ }^{14}$ Ignacio Obeso, PhD, ${ }^{15}$ Jose Ángel Pineda-Pardo, PhD, ${ }^{15}$ Roberto Cilia, MD, ${ }^{16}$ Benedicte Ballanger, PhD, ${ }^{17}$ Martin Niethammer MD, ${ }^{4}$ and Jon A. Stoessl, MD, ${ }^{18}$ on behalf of IPMDS-Neuroimaging Study Group ${ }^{1}$

${ }^{1}$ Morton and Gloria Shulman Movement Disorder Unit \& E.J. Safra Parkinson Disease Program, Neurology Div/Dept. Medicine, Toronto Western Hospital, UHN; Krembil Research Institute, UHN; Research Imaging Centre,

Campbell Family Mental Health Research Institute, CAMH, University of Toronto, Ontario, Canada

${ }^{2}$ University of Michigan \& Veterans Administration Medical Center, Ann Arbor, Michigan, USA

${ }^{3}$ Neurology, Radiology, Neuroscience, Physical Therapy \& Occupational Therapy, Washington University in St. Louis, St. Louis, Missouri, USA

${ }^{4}$ Center for Neurosciences, The Feinstein Institute for Medical Research, Manhasset, New York, USA

${ }^{5}$ Newcastle Magnetic Resonance Centre \& Positron Emission Tomography Centre, Newcastle University, Campus for Ageing \& Vitality, Newcastle upon Tyne, United Kingdom

${ }^{6}$ Multimodal Neuroimaging Group-Department of Nuclear Medicine Department of Neurology-University of Cologne, Institute of Neuroscience and Medicine, Jülich Research Center, German Center for Neurodegenerative Diseases (DZNE), Germany

${ }^{7}$ Neurology Imaging Unit, Centre of Neuroinflammation and Neurodegeneration, Division of Brain Sciences, Hammersmith Campus, Imperial College London, United Kingdom

${ }^{8}$ Neurodegeneration Imaging Group, Department of Basic and Clinical Neuroscience, Institute of Psychiatry, Psychology and Neuroscience, King's College London, London, United Kingdom

${ }^{9}$ Hospices Civils de Lyon, Hopital Neurologique Pierre Wertheimer, Université Lyon 1; CNRS, Centre de Neurosciences Cognitives, UMR 5229, Lyon, France

${ }^{10}$ Department of Clinical and Experimental Medicine, Movement Disorders and Parkinson Center, University of Pisa, Italy

${ }^{11}$ National Institute of Radiological Sciences, National Institutes for Quantum and Radiological Science and Technology, Chiba, Japan

${ }^{12}$ Division of Clinical Neurosciences, Turku University Hospital; Department of Neurology, University of Turku; Turku PET Centre, University of Turku, Turku, Finland

${ }^{13}$ Cognitive \& Movement Disorders Clinic, Sunnybrook Health Sciences Centre; Hurvitz Brain Sciences Research Program, Sunnybrook Research Institute, University of Toronto, Toronto, Ontario, Canada

${ }^{14}$ Movement Disorder and Parkinson's Disease Program, CEMIC University Hospital, Buenos, Aires, Argentina

${ }^{15}$ Centro Integral de Neurociencias (CINAC), Hospitales Madrid Puerta del Sur \& Centro de Investigación Biomédica en Red,

Enfermedades Neurodegenerativas (CIBERNED), Madrid, Spain

${ }^{16}$ Parkinson Institute, ASST Gaetano Pini-CTO, Milan, Italy

${ }^{17}$ INSERM, U1028; CNRS, UMR5292; Lyon Neuroscience Research Center, Neuroplasticity \& Neuropathology of Olfactory Perception Team, University Lyon, France

${ }^{18}$ Pacific Parkinson's Research Centre \& National Parkinson Foundation Centre of Excellence,

University of British Columbia \& Vancouver Coastal Health, Vancouver, British, Columbia, Canada

\begin{abstract}
Molecular imaging has proven to be a powerful tool for investigation of parkinsonian disorders. One current challenge is to identify biomarkers of early changes that may predict the clinical trajectory of parkinsonian disorders. Exciting new tracer developments hold the potential for in vivo markers of underlying pathology. Herein, we provide an overview of molecular
\end{abstract}

imaging advances and how these approaches help us to understand PD and atypical parkinsonisms. (C) 2017 International Parkinson and Movement Disorder Society.

Key Words: Parkinson's disease; atypical parkinsonism; PET; dopamine; serotonin; acetylcholine; amyloid; tau; FDG
${ }^{*}$ Correspondence to: Dr. Antonio P. Strafella, Toronto Western Hospital, 399 Barthurst Street, Toronto, Ontario, Canada, M5H 2S8; E-mail: antonio.strafella@uhn.ca; antonio.strafella@camh.ca

Relevant conflicts of interest/financial disclosures: Nothing to report. Full financial disclosures and author roles may be found in the online version of this article.
Received: 14 October 2016; Revised: 21 November 2016; Accepted: 27 November 2016

Published online 2 February 2017 in Wiley Online Library (wileyonlinelibrary.com). DOI: 10.1002/mds.26907 
In the last decade, the molecular imaging field has entered a new era of exploration into human brain diseases and has proven to be a powerful tool for investigation of the human brain, which is characterized by highly interconnected regions and networks involved in motor, cognitive, and behavioral functions. Whereas several of the recent molecular imaging approaches are still under development and probably not yet able to provide definitive answers, they represent valuable tools to improve our understanding of basic molecular mechanisms and pathophysiological processes underlying parkinsonian disorders. One current challenge is to identify biomarkers of early changes that predict at the group-level progression and development of selected manifestations of parkinsonian disorders. On an individual level, it is unclear how helpful molecular imaging techniques (i.e., PET and single-photon emission computed tomography [SPECT]) may help stratify risk for developing motor and behavioral complications. This personalized medicine approach, though still in its infancy in Parkinson's disease (PD) and related disorders, has future potential for identifying subgroups of patients for targeted clinical trials of novel agents. Molecular imaging, with newly developed radiopharmaceuticals, now has increased potential to reveal underlying pathological processes, such as changes in receptors (e.g., dopaminergic and nondopaminergic), blood flow, metabolism, neuroinflammation, and abnormal protein deposition. Furthermore, some molecular imaging measures may provide biomarkers of target engagement or efficacy for clinical trials. Whereas most imaging studies focused on CNS abnormalities, a few interesting studies imaged peripheral organs in PD, ${ }^{1}$ raising the issue of their practical value. Although most neuroimaging investigations focused on PD, some have addressed the atypical parkinsonisms.
This knowledge gap certainly creates the need for new molecular imaging approaches and biomarkers for these atypical parkinsonian disorders still not sufficiently understood. In this article, we will provide an overview of high-affinity radiotracers and molecular imaging advances and how these approaches have had an impact in understanding PD and atypical parkinsonisms.

\section{Molecular Imaging of PD and Its Progression}

\section{What Have We Learned From Imaging the Dopaminergic System?}

Degeneration of nigrostriatal neurons is responsible for most of the classical motor manifestations of early PD. The underlying pathophysiology in PD includes $\alpha$ synuclein deposition in cytoplasmic inclusions, called Lewy bodies, found in residual neurons in areas such as the $\mathrm{SNpc}$, but $\alpha$-synuclein also may be deposited in dystrophic neurons in striatal or cortical regions (Lewy neurites). Projection neurons like nigrostriatal afferents have long, poorly myelinated axons and may be particularly vulnerable; Lewy neurites may appear before cell body damage. ${ }^{2}$

Although dopamine levels (Fig. 1) cannot be measured directly using imaging, several approaches can be used to assess altered function of nigrostriatal dopaminergic nerve terminals (Fig. 2). The most widely accessible approach is the use of a marker for the dopamine transporter (DAT). Several positron- or photon-emitting molecules are available for use with PET or SPECT, respectively. These ligands have varying degrees of selectivity for the DAT over other monoamine reuptake transporters, and pharmacokinetic profiles differ from one tracer to another.

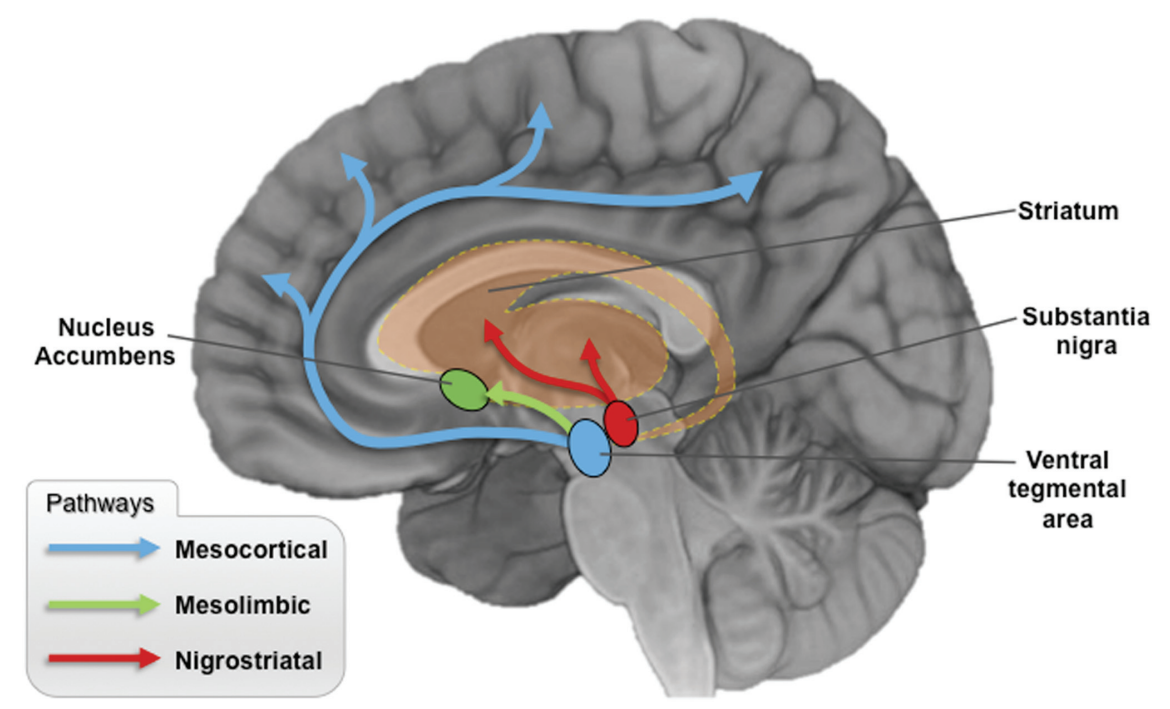

FIG. 1. Ascending nigrostriatal (red), mesolimbic (green), and mesocortical (blue) dopaminergic pathways. 


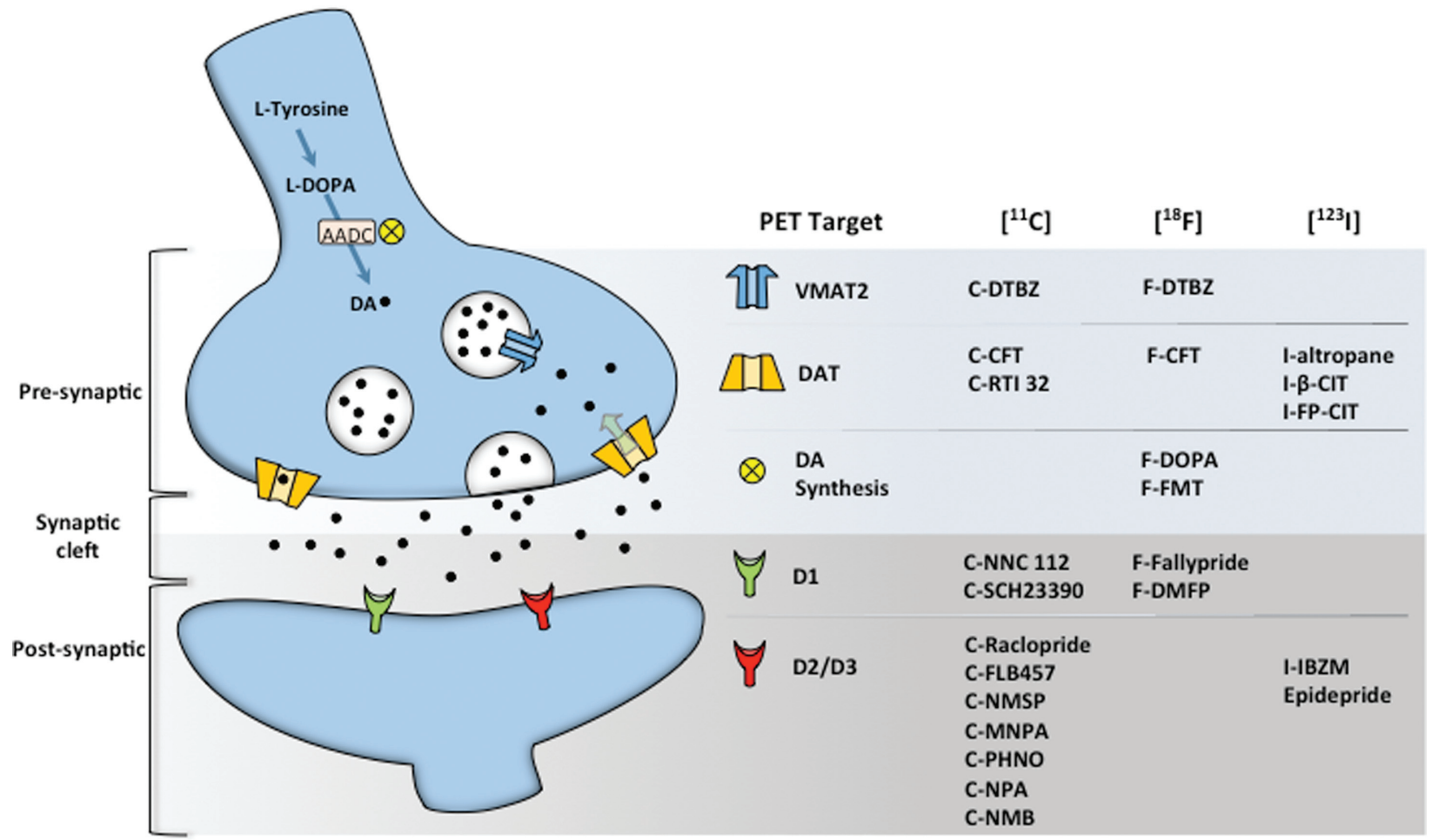

FIG. 2. Dopaminergic nerve terminal and various PET radiotracers for the assessment of its integrity. DA, dopamine agonist.

This may be of some practical importance because some tracers (e.g., ${ }^{123} \mathrm{I}-\beta$-CIT; ${ }^{123} \mathrm{I}-(-)-2 \beta$-carbomethoxy-3 $\beta$-(4-iodophenyl)tropane) do not reach steady state for several hours, mandating patients to return for imaging the day following tracer injection, whereas others $\left({ }^{11} \mathrm{C}\right.$-d-threo-methylphenidate, ${ }^{18} \mathrm{~F}$-fluoropropyl$\beta$-CIT, and ${ }^{123}$ I-fluoropropyl-CIT) can be imaged within 1 to 2 hours of tracer injection. An alternative approach is to label the DAT ligand with ${ }^{99 \mathrm{~m}} \mathrm{Tc}$, which is an isotope that is widely used in clinical nuclear medicine. Striatal DAT binding correlates with loss of nigrostriatal dopamine terminals, but may only correlate with nigral neurons when that loss does not exceed $50 \%{ }^{3}$ whereas direct imaging of midbrain uptake correlates with residual nigral neurons ${ }^{4}$; thus, striatal DAT may not reflect disease progression beyond mild-to-moderate disease. ${ }^{3,5,6}$ Striatal or nigral uptake may therefore be a useful imaging biomarker.

A second approach to determining the integrity of the presynaptic dopaminergic terminal is to study binding to vesicular monoamine transporter type 2 (VMAT2). VMAT2 is responsible for packaging monoamines into their appropriate synaptic vesicles, and binding is accordingly not specific to dopamine neurons. However, more than $90 \%$ of striatal VMAT2 binding is to dopaminergic nerve terminals. VMAT2 binding is typically studied with ${ }^{11} \mathrm{C}$-dihydrotetrabenazine (DTBZ), which is not widely available, and studies can therefore only be performed at a few sites. However, an $\mathrm{F}^{18}$-labeled radiotracer is now commercially available, increasing the accessibility of these measures. VMAT2 binding may be less subject to regulation than DAT binding, ${ }^{7}$ but this remains controversial. ${ }^{8}$ It may have some sensitivity to vesicular dopamine levels, such that VMAT2 binding may be increased in the rare situation where nerve terminals are preserved but are depleted of dopamine. $^{9}$

The original means of studying dopaminergic function was with the use of $6{ }^{18} \mathrm{~F}$-fluoro-L-dopa, which, like levodopa, is taken up by monoaminergic neurons, decarboxylated to (fluoro)dopamine, and, in the healthy brain, packaged in synaptic vesicles. Also, analogous to markers for DAT and VMAT2, fluorodopa uptake declines with disease progression and weakly inversely correlates with clinical severity, at least for mild-to-moderate degrees of disease severity. ${ }^{3}$ However, the interpretation of fluorodopa scans is somewhat more complicated, in that uptake reflects not only the (unidirectional) decarboxylation of fluorodopa to fluorodopamine, but also the egress of trapped fluorodopamine from synaptic vesicles. This can be used to estimate dopamine turnover, which increases with disease severity. ${ }^{10,11}$

All of these presynaptic markers of dopaminergic function show a very similar pattern in $\mathrm{PD}$, with asymmetric involvement of the striatum, and a rostralcaudal gradient in which the posterior putamen is maximally affected and the caudate nucleus least. Whereas this rostral-caudal gradient is preserved throughout the course of the illness, ${ }^{12}$ the decline in 


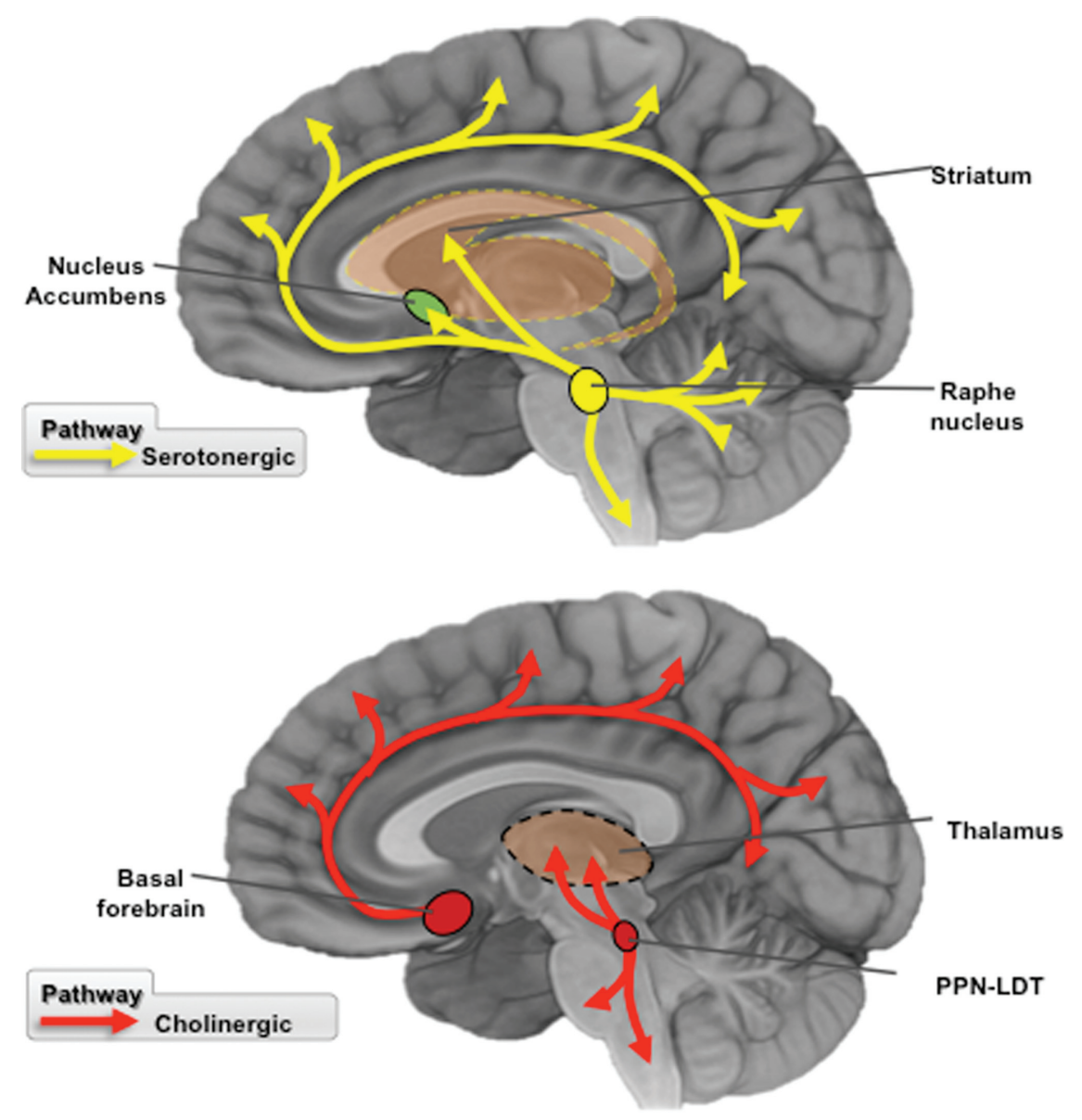

FIG. 3. (Top) Distribution of the serotonergic pathways (yellow); (bottom) distribution of the cholinergic pathway (red). PPN-LDT, pedunculopontine and laterodorsal nuclei.

dopaminergic markers over time is better described by an exponential, rather than a linear, relationship, where the majority of change in the putamen has taken place typically within the first 5 years, akin to postmortem observations, ${ }^{12}$ which have demonstrated almost total loss of tyrosine hydroxylase immunoreactivity within this time. ${ }^{6}$

Concurrent studies of multiple markers reveal that in early disease stages ( $\mathrm{H} \& \mathrm{Y}$ stage I), the threshold for clinical manifestations was $29 \%$ to $44 \%$ of normal values for DAT binding, $38 \%$ to $49 \%$ for VMAT2 binding, and $48 \%$ to $62 \%$ for fluorodopa uptake. ${ }^{13}$ The more-severe involvement of DAT binding may, in part, reflect downregulation of the DAT in early disease, whereas lesser involvement of fluorodopa uptake may reflect upregulation of decarboxylase activity in surviving dopamine neurons and/or expression of decarboxylase by serotonergic neurons. In studies conducted in nonhuman primates with unilateral internal carotid infusion of different doses of MPTP, it was found that the loss of only $30 \%$ to $35 \%$ of striatal terminals in nonhuman primates were able to generate motor parkinsonism and perhaps, more important, motor parkinsonism correlated with the nigral cell counts rather than the terminal field measures. ${ }^{14}$ In these animal models, $\left[{ }^{18} \mathrm{~F}\right]$-6-fluorodopa, $\left[{ }^{11} \mathrm{C}\right]$ CFT (DAT biomarker), and ${ }^{11} \mathrm{C}-\mathrm{DTBZ}$ correlated with striatal dopamine and fiber density, a reflection of terminal field function, but interestingly only correlated with nigral cell number within a limited range of cell loss (less than $50 \%$ ), ${ }^{3}$ as mentioned also above. In contrast, whereas PET measures of midbrain uptake of either VMAT2 or DAT correlated well throughout the full range of severity of nigrostriatal injury with stereologic counts of nigral dopaminergic neuronal cell bodies ${ }^{4}$ midbrain uptake of fluorodopa did not, thus suggesting that the midbrain measures may provide a better biomarker of severity of nigrostriatal injury. Other studies as well showed evidence that serial assessments with multiple markers provide an effective approach to evaluate evolution of dopaminergic depletion in MPTP monkeys. ${ }^{15,16}$

In a cohort of patients with sporadic PD studied longitudinally over several years, de la FuenteFernandez and colleagues ${ }^{17}$ estimated that VMAT2 binding declined 17 years before disease onset, followed by DAT binding 13 years before, whereas decline in fluorodopa uptake occurs last, only 6 years 


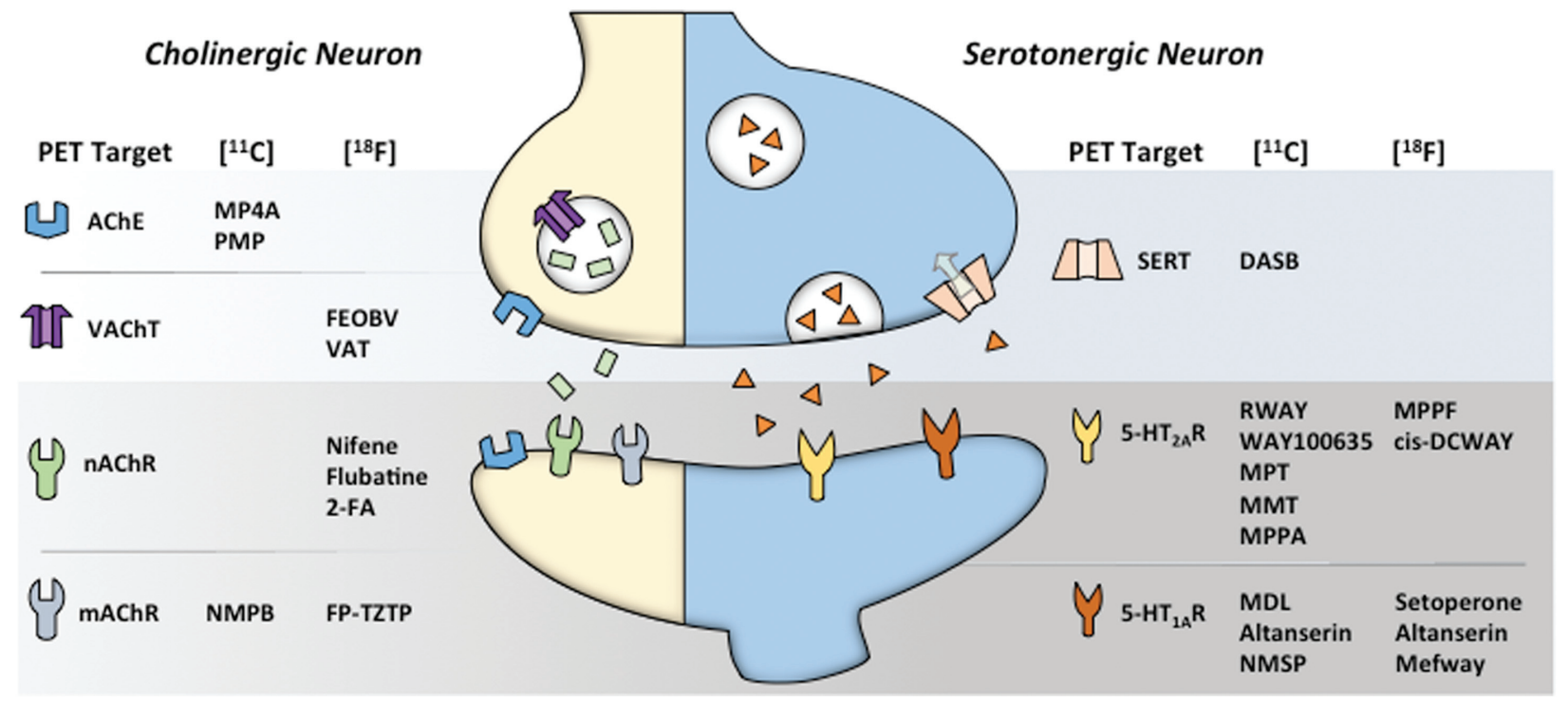

FIG. 4. Cholinergic (left) and serotonergic (right) nerve terminal and various PET radiotracers for the assessment of their integrity.

before disease onset. However, whereas fluorodopa uptake does not decline until later, dopamine turnover increases relatively early, an estimated 8 years before disease onset in sporadic PD, ${ }^{10}$ and years or even decades before the expected age of onset in patients with LRRK2 mutations. ${ }^{18}$ Consistent with the latter observation, imaging studies have shown evidence of dopaminergic dysfunction in subjects with a number of pathogenic mutations. The A53T and A53E mutations in the alpha-synuclein gene (SNCA) can be associated with early, relatively symmetrical defects in presynaptic dopaminergic function. ${ }^{19,20}$ Additionally, recessive Parkin $^{21-23}$ and PINK1 $^{19}$ mutations appear to be mostly associated with symmetrical dopaminergic losses, whereas in carriers of more-frequent LRRK2 and GBA mutations, the dopaminergic defect is practically indistinguishable from that of sporadic PD. ${ }^{19,24}$ In $G B A$-associated PD, the severity of dopaminergic dysfunction is related to the degree of glucocerebrosidase enzymatic activity reduction induced by the specific GBA mutation: Carriers of mild mutations (e.g., N370S) overlap with PD noncarriers, whereas PD carriers of severe mutations (e.g., L444P) have a similar phenotype to dementia with Lewy bodies. ${ }^{25}$

Many investigators have proposed that dopamine release may also be a valid method to evaluate dopaminergic functions. This can be estimated by exploiting (Fig. 2) the relatively high affinity of $\left[{ }^{11} \mathrm{C}\right]-$ raclopride, $\quad\left[{ }^{11} \mathrm{C}\right]-(+)-\mathrm{PHNO}, \quad\left[{ }^{18} \mathrm{~F}\right]$ fallypride, or $\left[{ }^{11}\right.$ C]FLB-457 for postsynaptic D2/D3 dopaminergic receptors, such that radioligand binding is subject to competition from endogenous dopamine. ${ }^{26,27} \mathrm{~A}$ change in binding potential can be used to estimate dopamine release at the striatal $\left(\left[{ }^{11} \mathrm{C}\right]\right.$-raclopride or $\left.\left[{ }^{11} \mathrm{C}\right]-(+)-\mathrm{PHNO}\right)$ or extrastriatal level $\left(\left[{ }^{18} \mathrm{~F}\right]\right.$ fallypride or $\left.\left[{ }^{11} \mathrm{C}\right] \mathrm{FLB}-457\right)$ in response to medications, behavioral stimuli, and brain stimulation techniques. More-detailed descriptions of these applications are reported below in the section related to behavioral complications in PD.

\section{How Imaging of Nondopaminergic Changes Contributed to our Current Knowledge?}

A large body of evidence suggests that nonopaminergic mechanisms may also contribute to the pathophysiology of PD (Figs. 3 and 4). Studies conducted with serotonergic PET tracers (Figs. 3 and 4) have shed some light on understanding the role of this neurotransmitter. A PET biomarker of the serotonin transporter (SERT), that is, $\left[{ }^{11} \mathrm{C}\right] \mathrm{DASB}$, has shown a nonlinear, gradual loss of presynaptic serotonergic terminal function in the subcortical and cortical areas during PD progression. ${ }^{28,29}$ Subsequent reports have suggested its potential role in the pathophysiology of L-dopa-induced dyskinesias (LIDs). ${ }^{30}$ Using $\left[{ }^{11} \mathrm{C}\right] \mathrm{DASB}$ PET together with a series of $\left[{ }^{11} \mathrm{C}\right]$ raclopride PET scans, these studies demonstrated that PD patients with LIDs exhibited relative preserved striatal serotonergic terminals (compared to profound degeneration of dopaminergic terminals), possibly responsible for the synaptic dopaminergic levels, and that oral administration of the $5-\mathrm{HT}_{1 \mathrm{~A}}$ agonist, buspirone (before $\mathrm{L}-$ dopa), reduced L-dopa-related striatal synaptic dopamine increases and attenuated LIDs. ${ }^{30,31}$ Serotonergic PET imaging also indicated similar mechanisms underlying the development of graft-induced dyskinesias (GIDs) in transplanted PD patients. Studies with $\left[{ }^{11} \mathrm{C}\right] \mathrm{DASB}$ PET together with dopaminergic biomarkers, that is, $\left[{ }^{18} \mathrm{~F}\right]$ fluorodopa, demonstrated serotonergic hyperinnervation and elevated serotonin/ dopamine terminal ratio in the grafted tissue of 
transplanted PD patients who developed GIDs. ${ }^{32,33}$ GIDs were markedly attenuated by systemic administration of $5-\mathrm{HT}_{1 \mathrm{~A}}$ agonist buspirone, which, by reducing transmitter release from serotonergic neurons, may suggest that dyskinesias were likely related to the serotonergic hyperinnervation.

Phosphodiesterase 10A (PDE10A) has a key role in the regulation of dopaminergic signaling in striatal pathways and in promoting neuronal survival. PDE10A is a basal ganglia expressed dual substrate enzyme, which regulates cyclic adenosine monophosphate and cyclic guanosine monophosphate signaling cascades. PET studies using $\left[{ }^{11} \mathrm{C}\right] \mathrm{IMA} 107$, a biomarker of PDE10A in vivo, have demonstrated reduced striatal levels of PDE10A, which correlated with PD duration and disease burden scores such as motor disability and severity of LIDs, ${ }^{34}$ thus confirming the complex interaction of dopaminergic and nondopaminergic mechanisms underlying the pathophysiology of PD.

Consistent with this observation, voxel-based mapping of cerebral blood flow and metabolic activity has also revealed stereotyped, spatially distributed disturbances of regional brain function in PD patients. Functional brain imaging with $\left[{ }^{18} \mathrm{~F}\right]$-fluorodeoxyglucose PET has provided a means of detecting and quantifying highly specific spatial covariance patterns associated with a variety of neurodegenerative disorders, including PD. ${ }^{35}$ The PD-related metabolic pattern (PDRP), identified in resting-state metabolic imaging data analyzed using spatial covariance mapping, is characterized by increased pallidothalamic and pontine metabolic activity, associated with reductions in premotor cortex and parietal association areas. Expression values for the PDRP measured in individual subjects correlates significantly with loss of presynaptic nigrostriatal dopaminergic integrity, as well as with independent clinical ratings of motor dysfunction. ${ }^{36,37}$ Notably, topographically similar metabolic network abnormalities have been recently identified in nonhuman primates with experimental parkinsonism attributed to systemic MPTP exposure. ${ }^{38,39}$ In a recent blinded surgical trial of gene therapy for PD, the rate of PDRP progression measured over 1 year was not affected by placebo treatment. ${ }^{40}$ In contrast, reductions in PDRP expression have been found consistently during L-dopa therapy and STN-DBS and significantly correlated with clinical improvement. ${ }^{41}$ This suggests that PDRP can be considered a reliable biomarker of treatment response. PDRP expression is also sensitive to network changes occurring before the appearance of motor symptoms. Expression levels of this network have recently been found to be abnormally elevated in the clinically unaffected hemisphere of early PD patients and in "preclinical" subjects with rapid eye moverment sleep behavior disorder. ${ }^{36,42}$
Neuroinflammation is also considered to play an important role in PD. ${ }^{43-45}$ Translocator protein 18 $\mathrm{kDa}$ (TSPO) has been investigated as a potential biomarker of inflammation. Elevated TSPO expression was primarily quantified using $\left[{ }^{11} \mathrm{C}\right](R)$ PK11195 PET. To date, a few studies have investigated neuroinflammation in PD patients using $\left[{ }^{11} \mathrm{C}\right](\mathrm{R}) \mathrm{PK} 11195$ PET. Whereas some studies have found elevated TSPO binding in the nigrostriatal regions, ${ }^{46-48}$ others did not support these observations. ${ }^{49}$ These limitations have prompted the development of second-generation TSPO radioligands (i.e., $\left[{ }^{11} \mathrm{C}\right]$ PBR28; $\left[{ }^{18} \mathrm{~F}\right]$-FEPPA, etc.), which present three patterns of binding affinity based on a genetic polymorphism: low-affinity binders; mixed-affinity binders (MABs); and high-affinity binders (HABs). ${ }^{50}$ These different genotype binding affinity patterns account for some of the large interindividual variability in the outcome measures ${ }^{50}$ and can be predicted by a single-nucleotide polymorphism, rs6971 located in the exon 4 of the TSPO gene resulting in a nonconservative amino-acid substitution at position 147 from alanine to threonine (Ala147Thr) in the fifth transmembrane domain of the TSPO protein. Using these second-generation TSPO radioligands (i.e., $\left[{ }^{18} \mathrm{~F}\right]$ FEPPA), Koshimori and colleagues, ${ }^{43}$ though noting a significant genotype effect (MABs vs. HABs) on the $\left[{ }^{18} \mathrm{~F}\right]$-FEPPA volume distribution $(\mathrm{Vt})$, did not observe any disease effect on differential TSPO binding in the striatum of PD patients. Other studies, however, in individuals with Alzheimer's disease $(\mathrm{AD})$ have shown evidence of significant increase in $\left[{ }^{18} \mathrm{~F}\right]$-FEPPA Vt in HABs, but not MABs. ${ }^{51}$

\section{Mild Cognitive Impairment and Dementia in PD}

\section{Have Different Imaging Biomarkers Helped to Understand Cognitive Deterioration?}

The etiology of cognitive decline in PD is heterogeneous. Imaging biomarker studies of cognitive impairment in PD have targeted neurotransmitter systems, pathological protein deposits, and glucose metabolic or perfusion changes. Prospective evaluation of glucose metabolic changes have shown that incident dementia initially may present as a predominant hypometabolic posterior cortical pathology involving the visual association cortex, inferior parietal and temporal regions, the posterior cingulum, and precuneus in PD. ${ }^{52,53}$ Subsequent progression to dementia is associated with mixed subcortical, including the thalamus and caudate nuclei, and widespread cortical changes that involve the anterior cortices as well. ${ }^{52,54}$ Spatial covariance mapping has been particularly useful in providing information regarding the network topography that underlies cognitive dysfunction in PD. ${ }^{35}$ Indeed, this approach has revealed a distinct PD 
cognition-related pattern (PDCP) characterized by metabolic reductions in the medial prefrontal, premotor, and parietal association regions, with relative increases in the cerebellar vermis and dentate nuclei. In cross-sectional analyses, increased PDCP expression is associated with more-severe cognitive impairment. PDCP expression is abnormally elevated, even in PD patients without evidence of cognitive impairment, and highest in those with dementia. ${ }^{35}$ Of note, PD subjects whose executive function improved with Ldopa administration ("responders") also exhibited concurrent reductions in PDCP expression. By contrast, PD subjects showing no cognitive improvement ("nonresponders") exhibited no change in PDCP expression with L-dopa. ${ }^{55}$ Both groups, however, exhibited significant L-dopa-mediated reductions in PDRP expression, underscoring the functional distinction between the cognitive and motor networks. These findings, together with a recent study on glucose metabolism in groups of patients along the spectrum of parkinsonism to dementia (PD, PD with dementia [PDD], DLB, and AD), support the notion that glucose metabolism patterns may reflect more the clinical syndrome than the underlying pathology. ${ }^{56}$

An intriguing dual syndrome cognitive hypothesis has been proposed, which posits that the high frequency of frontostriatal executive dysfunction in PD may relate to common dopaminergic deficits, ${ }^{57,58}$ and that the development of dementia is associated with more widespread and posterior cortical changes secondary to additional pathologies, including cholinergic deficits. ${ }^{59,60}$ Although dopaminergic denervation affects specific cognitive functions in $\mathrm{PD},{ }^{58}$ striatal and limbofrontal dopaminergic changes are present in nondemented PD subjects, ${ }^{58}$ but their presence is not sufficient to explain the full development of dementia in PD. ${ }^{61}$ In contrast, greater cholinergic denervation is shown consistently in PD dementia compared to PD. ${ }^{61,62}$ These observations support a more complex pathophysiological model of interacting dopaminergic (Fig. 1) and cholinergic degenerative (Figs. 3 and 4) changes producing cognitive dysfunctions in PD. ${ }^{63-65}$ However, imaging studies confirmed as well a significant relationship between in vivo measures of elevated cortical and, in particular, striatal $\beta$-amyloid deposits (measured with $\left.\left[{ }^{11} \mathrm{C}\right] \mathrm{PIB}\right)$ and greater cognitive impairment in PD. ${ }^{66,67}$ However, the risk of having an abnormal $\left[{ }^{11} \mathrm{C}\right]$ PIB PET study in PDD substantially underestimated the risk of abnormal $\beta$-deposition in the brain at autopsy in people with PD and dementia. ${ }^{68,69}$ Interestingly, $\beta$-amyloid deposition measured either in vivo with $\left[{ }^{11} \mathrm{C}\right]$ PIB or at autopsy with immunohistochemistry did not necessarily reflect coexisting $\mathrm{AD}$, given that those with dementia attributed to $\mathrm{AD}$ would present marked pathologic deposition of both $\beta$-amyloid and tau. Furthermore, the distribution of $\beta$-amyloid measured with $\left[{ }^{11} \mathrm{C}\right]$ PIB in PDD has a significantly different pattern in the brain demonstrated by principal components analysis compared to those with $\mathrm{AD} .{ }^{70}$ Together, these data indicate the relevance of $\beta$-amyloid brain deposition in PD, but suggest that this does not merely reflect the full spectrum of $\mathrm{AD}$ pathology.

All of these data demonstrate that neurotransmitter and proteinopathy changes have independent and incremental contributions to the cognitive syndrome in PD. ${ }^{65}$ However, other factors (i.e., neuroinflammation) may also play a role. In fact, it has been shown that there may exist a direct relationship between $\beta$ amyloid load and levels of microglial activation in PDD subjects, ${ }^{71}$ suggesting that neuroinflammation may be an early phenomenon, before the dementia onset, and that amyloid along with microglial activation could together contribute not only to the local neuronal dysfunction, but also to the more remote neuronal disconnection. ${ }^{71}$ Thus, for future studies, there is a need for new ligands for not only neurotransmission, in particular, norepinephrine, but also new neuroinflammatory (besides TSPO-binding tracers) and proteinopathy targets, especially tracers to visualize neurofibrillary tau and $\alpha$-synuclein protein aggregates for more comprehensive understanding of the cognitive impairment syndrome in PD.

\section{Behavioral and Affective Complications in PD}

\section{What Molecular Imaging Has Taught Us About Behavioral Spectrum Disorders}

There is evidence of a behavioral spectrum disorder ranging from hypodopaminergic levels responsible for apathy, anxiety, and depression, as described in the withdrawal dopaminergic syndrome to hyperdopaminergic syndrome, including impulse control disorders (ICDs), hallucinations, and psychosis. ${ }^{72,73}$ Often, depression may manifest before the diagnosis of PD; however, there is considerable evidence suggesting that this complication can be associated with a more widespread neurodegenerative process. Imaging reports seem to suggest involvement of both dopaminergic and serotonergic systems. Whereas studies using the DAT radioligand (i.e., TRODAT-1) found significantly higher DAT density in the striatum of depressed PD patients, ${ }^{74}$ other investigations with SERT (i.e., $\left.\left[{ }^{11} \mathrm{C}\right] \mathrm{DASB}\right)$ showed abnormal serotonergic neurotransmission in the raphe nuclei and limbic structures, which correlated with depression measures. ${ }^{75}$ The serotonergic alteration in depression was confirmed by another PET study using ${ }^{18} \mathrm{~F}-\mathrm{MPPF}$, a selective serotonin $1 \mathrm{~A}$ receptor antagonist. ${ }^{76}$ Apathy may also occur in up to $40 \%$ of PD patients, and, although clinically distinct from depression, the two are often 
comorbid. $^{72}$ Anatomical and imaging reports have provided evidence that network abnormalities within the prefrontal-striatal circuit can lead to an apathetic behavior. Classically, apathy is the result of a disruption of "emotional-affective" mechanisms linked to the ventral striatum, ventromedial prefrontal cortex, and amygdala. ${ }^{77}$ PET studies with D2/D3 receptor antagonist [11C]-raclopride have shown several differences in dopaminergic binding and transmission in the mesocorticolimbic system between apathetic and nonapathetic PD patients. $^{78}$ [11C]-raclopride binding potential was increased in apathetic PD patients in the orbitofrontal cortex (OFC), cingulate cortex, dorsolateral prefrontal cortex, amygdala, as well as in the striatum, implying either (reactive) increase in D2/D3 receptor expression and/or reduction in endogenous synaptic dopamine. Other PET studies with [ $\left.{ }^{11} \mathrm{C}\right] \mathrm{RTI}-$ 32, a ligand with affinity to both dopamine and noradrenaline transporters, confirmed that the degree of apathy severity was inversely correlated with $\left[{ }^{11} \mathrm{C}\right] \mathrm{RTI}-32$ binding in the ventral striatum. ${ }^{79}$ Taken together, these observations seem to suggest that apathy in PD may result from severe dopamine abnormalities in the mesocorticolimbic system, leading to an impaired emotion reactivity and poor decision-making processes, ${ }^{77}$ as also demonstrated in nonhuman primate studies of apathetic behaviors after MPTP. ${ }^{80,81}$ However, from more recent evidence, the mechanism of apathy, depression, and anxiety in PD may be more complex and may differ according to the stage of the disease. In fact, in de novo PD, serotonergic, rather than dopaminergic, degeneration appears to play a significant role in this nonmotor triad. ${ }^{82}$

Whereas certain behavioral complications are often inherent to the disease process, others are mainly associated with symptomatic treatments. Dopamine agonists, for example, have been implicated in the development of ICDs. ${ }^{83}$ Susceptibility to these behavioral addictions is associated with increased striatal dopamine release ${ }^{84-86}$ and reduced DAT binding in the ventral striatum. ${ }^{87}$ Whereas abnormalities in dopaminergic processing in the ventral striatum are critical for the development of ICDs, prefrontal mechanisms may also play an important inhibitory role in these behaviors. Activation PET studies with $\mathrm{H}_{2}\left[{ }^{15} \mathrm{O}\right]$ before and after administration of a dopamine agonist in PD with and without gambling behavior found changes in brain areas implicated in impulse control and response inhibition (lateral orbitofrontal cortex, rostral cingulate zone, and amygdala). ${ }^{88}$ Although the agonist significantly increased regional cerebral blood flow $(\mathrm{rCBF})$ in these areas in healthy subjects, gamblers showed, in contrast, a significant reduction of activity. A subsequent PET study using the extrastriatal dopamine receptor ligand, $\left[{ }^{11} \mathrm{C}\right] \mathrm{FLB}-457,{ }^{89}$ found significant abnormalities in $\mathrm{D} 2$ receptor binding in the OFC and anterior cingulate cortex in PD patients with pathological gambling, thus confirming the role of prefrontal control in the development of ICDs. Similarly, $\left[{ }^{18} \mathrm{~F}\right]$ fluorodopa PET has shown abnormalities in the OFC of PD patients with ICDs. ${ }^{90}$ In PD patients, STN-DBS may also contribute to certain impulsive behavior associated with high-conflict decisions. ${ }^{91,92}$ An rCBF study with $\mathrm{H}_{2}\left[{ }^{15} \mathrm{O}\right]$ PET during a $\mathrm{Go} / \mathrm{NoGo}$ task showed a relationship between motor improvement and response inhibition. In particular, STN-DBS affected response inhibition, as revealed by an increase in commission errors in NoGo trials ${ }^{91}$ and stop signal task. ${ }^{92}$ These behavioral changes were accompanied by changes in synaptic activity characterized by a reduced activation in the cortical networks associated with proactive and reactive response inhibition. These observations suggest that modulation of STN with DBS, although it improves motor functions, may tend in parallel to favor the appearance of certain impulsive behaviors by acting on mechanisms involved in response initiation and/or selection. ${ }^{91}$ However, to date, the impact of DBS (and its interaction with dopamine agonist reduction) on the development of ICD is unclear and still quite controversial, given that studies using different approaches have shown conflicting results. ${ }^{93-95}$

Fatigue is a common nonmotor symptom in PD. Recent studies have reported that PD patients with higher level of fatigue may show anticorrelated metabolic changes in cortical regions associated with the salience (i.e., right insular region) and default (i.e., bilateral posterior cingulate cortex) networks. ${ }^{96}$ Other studies of dopaminergic and serotoninergic function in PD patients with and without fatigue demonstrated a serotoninergic denervation in the basal ganglia and related limbic circuits. ${ }^{97}$ PD patients with fatigue had significantly lower SERT binding than patients without fatigue in the basal ganglia structure. ${ }^{97}$ Additionally, voxel-based analysis identified reduced dopaminergic activity in caudate and insula and further SERT reductions in cingulate and amygdala in the fatigue group. All together, these findings provide the rationale for treatment strategies aiming to increase brain level of serotonin and serotoninergic transmission as potential treatment of this common complication in PD patients.

\section{Differentiating Atypical Parkinsonisms From PD}

\section{Is Molecular Imaging Helping Us?}

To date, most molecular imaging studies in parkinsonism have focused on investigating either dopaminergic changes or cerebral blood flow and metabolism. PSP and corticobasal syndrome (CBS) are common forms of atypical parkinsonism (APS) and, in early 
stages, can be sometimes quite difficult to diagnose given that they can overlap clinically with PD and other parkinsonian syndromes, including MSA. Previous imaging studies have reported in CBS either asymmetric hypoperfusion or reduced metabolism, mainly in the striatum, as well as parietal and frontal cortex contralateral to the affected limb. ${ }^{98}$ CBS may also be variably associated with asymmetric striatal dopamine denervation (e.g., and Cilia and colleagues ${ }^{99}$. Similarly, PSP patients may present with a variable pattern of hypometabolism in the fronto-striatal-thalamic regions depending on the clinical presentation and progression. ${ }^{98,100}$ Families with mutations in the progranulin gene presented profound imaging changes of asymmetric hypoperfusion on SPECT and parietal atrophy. ${ }^{101,102}$ Subsequent work in CBS identified that hypoperfusion within the left inferior parietal lobule, including the left angular gyrus, was associated with more severe ideomotor apraxia. Voxel-based spatial covariance mapping has also been used to identify disease-specific networks for MSA, PSP, and corticobasal degeneration. ${ }^{103,104}$ Importantly, an automated logistic regression algorithm based on pattern expression values has been developed to aid in discriminating individuals with idiopathic PD from those with atypical parkinsonian syndromes and in differentiating among the various forms of APS. This approach had excellent diagnostic specificity in an original data set $^{105}$ and in a subsequent validation sample. ${ }^{106}$ Other methods, such as relevance vector machine analysis, have also been used for single-case classification with promising results. ${ }^{107,108}$ Prospective validation studies are needed before the relative utility of these methods can be determined. Neuroinflammation may play an important role in various atypical parkinsonisms. To date, only a few studies have investigated neuroinflammation in these disorders using mainly first generation of radiotracers, that is, $\left[{ }^{11} \mathrm{C}\right](R) \mathrm{PK} 11195 .{ }^{109}$ Although the findings are highly suggestive, they require further confirmation.

Other studies assessed the diagnostic value of dopaminergic tracers using $\left({ }^{18} \mathrm{~F}\right)$-FP-CIT PET in differentiating PSP and MSA from PD. ${ }^{110}$ Compared to PD, PSP and MSA have more prominent DAT loss in the anterior caudate and ventral putamen, respectively. However, it should be emphasized that the pattern of presynaptic dopaminergic impairment is not felt to reliably differentiate among various neurodegenerative forms of parkinsonism. Studies in which presynaptic dopamine markers are combined with measures of postsynaptic dopamine receptors may help differentiate PD from atypical parkinsonian syndromes, but not between these various syndromes. Except in a few highly specialized centers, neuroimaging has had a very limited diagnostic value in the differential diagnosis of PSP, CBS, and other tauopathies. For this reason, the development of PET radiotracers specific for tau represents one of the most active and challenging areas in molecular imaging.

Several groups have recently reported encouraging results toward the development of selective tau imaging agents. ${ }^{111,112}\left[{ }^{18} \mathrm{~F}\right] \mathrm{T} 807$ (also known as $\left[{ }^{18} \mathrm{~F}\right]-\mathrm{AV}$ 1451) has been reported as having excellent selectivity for paired helical filaments of tau. ${ }^{11,112}$ This tracer demonstrated high affinity and selectivity as well as favorable in vivo properties, making this a potentially promising candidate as an imaging agent for tau. ${ }^{111}$ Another tracer, $\left[{ }^{11} \mathrm{C}\right] \mathrm{PBB} 3$, has also been recently applied to human studies, providing PET demonstration of spreading tau pathologies in transition from normal aging to advanced AD. ${ }^{113}$ PET imaging of sporadic four-repeat tau pathologies in PSP and CBD is currently being conducted, and preliminary data have indicated an increased retention of $\left[{ }^{11} \mathrm{C}\right] \mathrm{PBB} 3$ in multiple brain areas, including white matter, in patients with these disorders relative to age-matched controls. Studies of in vitro binding assays using brain homogenates found that the two tau probes, PBB3 and T807, do not compete with each other for binding sites in PSP tau aggregates. Other investigations with $\left[{ }^{18} \mathrm{~F}\right]-$ AV-1451 (i.e., $\left[{ }^{18} \mathrm{~F}\right] \mathrm{T} 807$ ) in PSP and CBS have shown preliminary findings with either increase ${ }^{114}$ or no retention. ${ }^{115}$

\section{Future Directions of Molecular Imaging: Need for Harmonization and Multicenter Collaboration}

Exciting new tracer developments hold the potential for in vivo markers of underlying pathology, which is of particular interest for interventions directly targeting protein aggregation. However, with increasingly diverse and sophisticated imaging approaches, it is now becoming more problematic than ever for nonexperts to assess the validity and significance of new studies. The scientific community should therefore move toward common standards and harmonization in molecular imaging. Good scientific practice criteria, including sample size, correction for multiple comparisons, and correction for the effects of age, motion, and partial volume effects, are among the most important issues to address. Anticipating excessive use of the term "biomarker" in imaging studies, we propose to use standardized terminology, which may help in the design of future experiments, especially when looking for surrogate markers in interventional studies. In line with the FDA/NIH BEST Resource (2016) propositions, a biomarker is defined as a characteristic that is measured as an indicator of a biological (pathogenic) process. A diagnostic biomarker should increase diagnostic accuracy for pathological or clinical entities 


\section{STRAFELLA ET A L}

in comparison to clinical judgment alone. In agreement with this definition, certain imaging characteristics may also serve to enrich specific features in a trial population (e.g., as a target verification tool in the case of tau PET). Monitoring biomarkers are measured serially and used to detect a change in the degree or extent of disease. This kind of imaging characteristic may serve as a biomarker that may predict clinical efficacy, but not likely to act as a surrogate endpoint given that such an imaging biomarker would not reflect unintended side effects. For PD, most valuable biomarkers would certainly be prodromal diagnostic biomarkers and monitoring biomarkers for disease progression at early/prodromal stages. For atypical parkinsonism, there often is a mismatch between clinical and pathological entities (e.g., CBS with AD pathology, PSP pathology with different clinical phenotypes). ${ }^{116,117}$ Therefore, diagnostic biomarkers in atypical parkinsonism should not be regarded as diagnostic for a clinical entity, unless the biomarker is pathologically validated. Though certainly fruitful, this kind of endeavor only seems feasible in a large, multicenter studies strategically focusing on the integration of postmortem information.

Acknowledgment: We thank Mark Jacobs for his help with the preparation of the figures and references.

\section{References}

1. Gjerloff T, Fedorova T, Knudsen K, et al. Imaging acetylcholinesterase density in peripheral organs in Parkinson's disease with 11 C-donepezil PET. Brain 2015;138:653-663.

2. Braak H, Ghebremedhin E, Rüb U, Bratzke H, Del Tredici K. Stages in the development of Parkinson's disease-related pathology. Cell Tissue Res 2004;318:121-134.

3. Karimi M, Tian L, Brown CA, et al. Validation of nigrostriatal positron emission tomography measures: critical limits. Ann Neurol 2013;73:390-396.

4. Brown CA, Karimi MK, Tian L, et al. Validation of midbrain positron emission tomography measures for nigrostriatal neurons in macaques. Ann Neurol 2013;74:602-610.

5. Kuramoto L, Cragg J, Nandhagopal R, et al. The nature of progression in Parkinson's disease: an application of non-linear, multivariate, longitudinal random effects modelling. PLoS One 2013; $8: e 76595$.

6. Kordower JH, Olanow CW, Dodiya HB, et al. Disease duration and the integrity of the nigrostriatal system in Parkinson's disease. Brain 2013;136(Pt 8):2419-2431.

7. Vander Borght T, Kilbourn M, Desmond T, Kuhl D, Frey K. The vesicular monoamine transporter is not regulated by dopaminergic drug treatments. Eur J Pharmacol 1995;294:577-583.

8. Tian L, Karimi M, Loftin SK, et al. No differential regulation of dopamine transporter (DAT) and vesicular monoamine transporter 2 (VMAT2) binding in a primate model of Parkinson disease. PLoS One 2012;7:e31439.

9. De La Fuente-Fernandez R, Furtado S, Guttman M, et al. VMAT2 binding is elevated in dopa-responsive dystonia: visualizing empty vesicles by PET. Synapse 2003;49:20-28.

10. Sossi V, de la Fuente-Fernandez R, Holden JE, Schulzer M, Ruth TJ, Stoessl J. Changes of dopamine turnover in the progression of Parkinson's disease as measured by positron emission tomography: their relation to disease-compensatory mechanisms. J Cereb Blood Flow Metab 2004;24:869-876.

11. Sossi V, de la Fuente-Fernandez R, Schulzer M, Troiano AR, Ruth TJ, Stoessl AJ. Dopamine transporter relation to dopamine turnover in Parkinson's disease: a positron emission tomography study. Ann Neurol 2007;62:468-474.

12. Nandhagopal R, Kuramoto L, Schulzer M, et al. Longitudinal progression of sporadic Parkinson's disease: a multi-tracer positron emission tomography study. Brain 2009;132(Pt 11):2970-2979.

13. Lee CS, Samii A, Sossi V, et al. In vivo positron emission tomographic evidence for compensatory changes in presynaptic dopaminergic nerve terminals in Parkinson's disease. Ann Neurol 2000;47:493-503.

14. Tabbal SD, Tian L, Karimi M, Brown CA, Loftin SK, Perlmutter JS. Low nigrostriatal reserve for motor parkinsonism in nonhuman primates. Exp Neurol 2012;237:355-362.

15. Blesa J, Juri C, Collantes M, et al. Progression of dopaminergic depletion in a model of MPTP-induced Parkinsonism in nonhuman primates. An (18)F-DOPA and (11)C-DTBZ PET study. Neurobiol Dis 2010;38:456-463.

16. Blesa J, Pifl C, Sanchez-Gonzalez MA, et al. The nigrostriatal system in the presymptomatic and symptomatic stages in the MPTP monkey model: a PET, histological and biochemical study. Neurobiol Dis 2012;48:79-91.

17. de la Fuente-Fernandez R, Schulzer M, Kuramoto L, et al. Agespecific progression of nigrostriatal dysfunction in Parkinson's disease. Ann Neurol 2011;69:803-810.

18. Sossi V, de la Fuente-Fernandez R, Nandhagopal R, et al. Dopamine turnover increases in asymptomatic LRRK2 mutations carriers. Mov Disord 2010;25:2717-2723.

19. McNeill A, Wu RM, Tzen KY, et al. Dopaminergic neuronal imaging in genetic Parkinson's disease: insights into pathogenesis. PLoS One 2013;8:e69190.

20. Martikainen MH, Paivarinta M, Hietala M, Kaasinen V. Clinical and imaging findings in Parkinson disease associated with the A53E SNCA mutation. Neurol Genet 2015;1:e27.

21. Ribeiro MJ, Thobois S, Lohmann E, et al. A multitracer dopaminergic PET study of young-onset parkinsonian patients with and without parkin gene mutations. J Nucl Med 2009;50:1244-1250.

22. Khan NL, Brooks DJ, Pavese N, et al. Progression of nigrostriatal dysfunction in a parkin kindred: an [18F]dopa PET and clinical study. Brain 2002;125(Pt 10):2248-2256.

23. Pavese N, Khan NL, Scherfler C, et al. Nigrostriatal dysfunction in homozygous and heterozygous parkin gene carriers: an $18 \mathrm{~F}$ dopa PET progression study. Mov Disord 2009;24:2260-2266.

24. Adams JR, van Netten $H$, Schulzer $M$, et al. PET in LRRK2 mutations: comparison to sporadic Parkinson's disease and evidence for presymptomatic compensation. Brain 2005;128(Pt 12):27772785 .

25. Cilia R, Tunesi S, Marotta G, et al. Survival and dementia in GBA-associated Parkinson disease: the mutation matters. Ann Neurol 2016; 80:662-673.

26. Laruelle M. Imaging synaptic neurotransmission with in vivo binding competition techniques: a critical review. J Cereb Blood Flow Metab 2000;20:423-451.

27. Willeit M, Ginovart N, Graff A, et al. First human evidence of damphetamine induced displacement of a D2/3 agonist radioligand: a $[11 \mathrm{C}]-(+)-P H N O$ positron emission tomography study. Neuropsychopharmacology 2008;33:279-289.

28. Politis M, Wu K, Loane C, et al. Staging of serotonergic dysfunction in Parkinson's disease: an in vivo 11C-DASB PET study. Neurobiol Dis 2010;40:216-221.

29. Politis M, Wu K, Loane C, et al. Serotonin neuron loss and nonmotor symptoms continue in Parkinson's patients treated with dopamine grafts. Sci Transl Med 2012;4:128ra141.

30. Politis $\mathrm{M}$, Wu K, Loane C, et al. Serotonergic mechanisms responsible for levodopa-induced dyskinesias in Parkinson's disease patients. J Clin Invest 2014;124:1340-1349.

31. Roussakis AA, Politis M, Towey D, Piccini P. Serotonin-to-dopamine transporter ratios in Parkinson disease. Neurology 2016;86: 1152-1158.

32. Politis M, Wu K, Loane C, et al. Serotonergic neurons mediate dyskinesia side effects in Parkinson's patients with neural transplants. Sci Transl Med 2010;2:38ra46.

33. Politis M, Oertel WH, Wu K, et al. Graft-induced dyskinesias in Parkinson's disease: high striatal serotonin/dopamine transporter ratio. Mov Disord 2011;26:1997-2003. 
34. Niccolini F, Foltynie T, Reis Marques T, et al. Loss of phosphodiesterase 10A expression is associated with progression and severity in Parkinson's disease. Brain 2015;138:3003-3015.

35. Niethammer M, Eidelberg D. Metabolic brain networks in translational neurology: concepts and applications. Ann Neurol 2012; $72: 635-647$

36. Holtbernd F, Ma Y, Peng S, et al. Dopaminergic correlates of metabolic network activity in Parkinson's disease. Hum Brain Mapp 2015;36:3575-3585.

37. Huang C, Tang C, Feigin A, et al. Changes in network activity with the progression of Parkinson's disease. Brain 2007;130: 1834-1846.

38. Ma Y, Peng S, Spetsieris PG, Sossi V, Eidelberg D, Doudet DJ. Abnormal metabolic brain networks in a nonhuman primate model of parkinsonism. J Cereb Blood Flow Metab 2012;32:633642.

39. Ma YL, Johnston TH, Peng SC, et al. Reproducibility of a parkinsonism-related metabolic brain network in non-human primates: a descriptive pilot study with FDG PET. Mov Disord 2015;30:1283-1288.

40. Ko JH, Feigin A, Mattis PJ, et al. Network modulation following sham surgery in Parkinson's disease. J Clin Invest 2014;124:36563666.

41. Asanuma K, Tang $\mathrm{C}, \mathrm{Ma} \mathrm{Y}$, et al. Network modulation in the treatment of Parkinson's disease. Brain 2006;129:2667-2678.

42. Wu P, Yu H, Peng S, et al. Consistent abnormalities in metabolic network activity in idiopathic rapid eye movement sleep behaviour disorder. Brain 2014;137:3122-3128.

43. Koshimori Y, Ko JH, Mizrahi R, et al. Imaging striatal microglial activation in patients with Parkinson's disease. PLoS One 2015; 10:e0138721.

44. McGeer PL, Itagaki S, Boyes BE, McGeer EG. Reactive microglia are positive for HLA-DR in the: substantia nigra of Parkinson's and Alzheimer's disease brains. Neurology 1988;38:1285-1291.

45. Imamura K, Hishikawa N, Sawada M, Nagatsu T, Yoshida M, Hashizume Y. Distribution of major histocompatibility complex class II-positive microglia and cytokine profile of Parkinson's disease brains. Acta Neuropathol 2003;106:518-526.

46. Gerhard A, Pavese N, Hotton G, et al. In vivo imaging of microglial activation with $[11 \mathrm{C}](\mathrm{R})$-PK11195 PET in idiopathic Parkinson's disease. Neurobiol Dis 2006;21:404-412.

47. Ouchi Y, Yagi S, Yokokura M, Sakamoto M. Neuroinflammation in the living brain of Parkinson's disease. Parkinsonism Relat Disord 2009;15(Suppl 3):S200-S204.

48. Ouchi Y, Yoshikawa E, Sekine Y, et al. Microglial activation and dopamine terminal loss in early Parkinson's disease. Ann Neurol 2005;57:168-175

49. Bartels AL, Willemsen AT, Doorduin J, de Vries EF, Dierckx RA, Leenders KL. [11C]-PK11195 PET: quantification of neuroinflammation and a monitor of anti-inflammatory treatment in Parkinson's disease? Parkinsonism Relat Disord 2010;16:57-59.

50. Owen DR, Howell OW, Tang SP, et al. Two binding sites for 3 HPBR28 in human brain: implications for TSPO PET imaging of neuroinflammation. J Cereb Blood Flow Metab 2010;30:16081618.

51. Suridjan I, Pollock BG, Verhoeff NP, et al. In-vivo imaging of grey and white matter neuroinflammation in Alzheimer's disease: a positron emission tomography study with a novel radioligand, " 18 F”-FEPPA. Mol Psychiatry 2015;20:1579-1587.

52. Bohnen NI, Koeppe RA, Minoshima S, et al. Cerebral glucose metabolic features of Parkinson disease and incident dementia: longitudinal study. J Nucl Med 2011;52:848-855.

53. Firbank MJ, Yarnall AJ, Lawson RA, et al. Cerebral glucose metabolism and cognition in newly diagnosed Parkinson's disease: ICICLE-PD study. J Neurol Neurosurg Psychiatry 2016 Oct 6. doi: 10.1136/jnnp-2016-313918. [Epub ahead of print]

54. Gonzalez-Redondo R, Garcia-Garcia D, Clavero P, et al. Grey matter hypometabolism and atrophy in Parkinson"s disease with cognitive impairment: a two-step process. Brain 2014;137(Pt 8): 2356-2367.

55. Mattis PJ, Tang CC, Ma Y, Dhawan V, Eidelberg D. Network correlates of the cognitive response to levodopa in Parkinson disease. Neurology 2011;77:858-865.
56. Granert O, Drzezga AE, Boecker H, et al. Metabolic topology of neurodegenerative disorders: influence of cognitive and motor deficits. J Nucl Med 2015;56:1916-1921.

57. Christopher L, Duff-Canning S, Koshimori Y, et al. Salience network and parahippocampal dopamine dysfunction in memoryimpaired Parkinson disease. Ann Neurol 2015;77:269-280.

58. Christopher L, Marras C, Duff-Canning S, et al. Combined insular and striatal dopamine dysfunction are associated with executive deficits in Parkinson's disease with mild cognitive impairment. Brain 2014;137(Pt 2):565-575.

59. Williams-Gray CH, Foltynie T, Brayne CE, Robbins TW, Barker RA. Evolution of cognitive dysfunction in an incident Parkinson's disease cohort. Brain 2007;130(Pt 7):1787-1798.

60. Kehagia AA, Barker RA, Robbins TW. Cognitive impairment in Parkinson's disease: the dual syndrome hypothesis. Neurodegener Dis 2013;11:79-92.

61. Klein JC, Eggers C, Kalbe E, et al. Neurotransmitter changes in dementia with Lewy bodies and Parkinson disease dementia in vivo. Neurology 2010;74:885-892.

62. Bohnen NI, Kaufer DI, Ivanco LS, et al. Cortical cholinergic function is more severely affected in parkinsonian dementia than in Alzheimer disease: an in vivo positron emission tomographic study. Arch Neurol 2003;60:1745-1748.

63. Bohnen NI, Albin RL, Muller ML, et al. Frequency of cholinergic and caudate nucleus dopaminergic deficits across the predemented cognitive spectrum of Parkinson disease and evidence of interaction effects. JAMA Neurol 2015;72:194-200.

64. Calabresi P, Picconi B, Parnetti L, Di Filippo M. A convergent model for cognitive dysfunctions in Parkinson's disease: the critical dopamine-acetylcholine synaptic balance. Lancet Neurol 2006;5:974-983.

65. Delgado-Alvarado M, Gago B, Navalpotro-Gomez I, JimenezUrbieta H, Rodriguez-Oroz MC. Biomarkers for dementia and mild cognitive impairment in Parkinson's disease. Mov Disord 2016;31:861-881.

66. Petrou M, Bohnen NI, Muller ML, Koeppe RA, Albin RL, Frey KA. Abeta-amyloid deposition in patients with Parkinson disease at risk for development of dementia. Neurology 2012;79:1161-1167.

67. Shah N, Frey KA, Muller ML, et al. Striatal and cortical $\beta$ amyloidopathy and cognition in Parkinson's disease. Mov Disord 2016;31:111-117.

68. Foster ER, Campbell MC, Burack MA, et al. Amyloid imaging of Lewy body-associated disorders. Mov Disord 2010;25:25162523.

69. Kotzbauer PT, Cairns NJ, Campbell MC, Willis AW, Racette BA, Tabbal SD, Perlmutter JS. Pathologic accumulation of alphasynuclein and $A \beta$ in Parkinson disease patients with dementia. Arch Neurol 2012;69:1326-1331.

70. Campbell MC, Markham J, Flores H, et al. Principal component analysis of PiB distribution in Parkinson and Alzheimer diseases. Neurology 2013;81:520-527.

71. Fan Z, Aman Y, Ahmed I, et al. Influence of microglial activation on neuronal function in Alzheimer's and Parkinson's disease dementia. Alzheimers Dement 2015;11:608-621.e7.

72. Aminian KS, Strafella AP. Affective disorders in Parkinson's disease. Curr Opin Neurol 2013;26(4):339-344.

73. Pondal M, Marras C, Miyasaki J, et al. Clinical features of dopamine agonist withdrawal syndrome in a movement disorders clinic. J Neurol Neurosurg Psychiatry 2013;84:130-135.

74. Felicio AC, Moriyama TS, Godeiro-Junior C, et al. Higher dopamine transporter density in Parkinson's disease patients with depression. Psychopharmacology (Berl) 2010;211:27-31.

75. Politis M, Wu K, Loane C, et al. Depressive symptoms in PD correlate with higher 5-HTT binding in raphe and limbic structures. Neurology 2010;75:1920-1927.

76. Ballanger $\mathrm{B}$, Klinger $\mathrm{H}$, Eche $\mathrm{J}$, et al. Role of serotonergic $1 \mathrm{~A}$ receptor dysfunction in depression associated with Parkinson's disease. Mov Disord 2012;27:84-89.

77. Pagonabarraga J, Kulisevsky J, Strafella AP, Krack P. Apathy in Parkinson's disease: clinical features, neural substrates, diagnosis, and treatment. Lancet Neurol 2015;14:518-531.

78. Thobois S, Ardouin C, Lhommee E, et al. Non-motor dopamine withdrawal syndrome after surgery for Parkinson's disease: 
predictors and underlying mesolimbic denervation. Brain 2010; 133(Pt 4):1111-1127.

79. Remy P, Doder M, Lees A, Turjanski N, Brooks D. Depression in Parkinson's disease: loss of dopamine and noradrenaline innervation in the limbic system. Brain 2005;128(Pt 6):1314-1322.

80. Brown CA, Campbell MC, Karimi M, et al. Dopamine pathway loss in nucleus accumbens and ventral tegmental area predicts apathetic behavior in MPTP-lesioned monkeys. Exp Neurol 2012; 236:190-197.

81. Tian L, Xia Y, Flores HP, Campbell MC, Moerlein SM, Perlmutter JS. Neuroimaging analysis of the dopamine basis for apathetic behaviors in an MPTP-lesioned primate model. PLoS One 2015;10:e0132064.

82. Maillet A, Krack P, Lhommee E, et al. The prominent role of serotonergic degeneration in apathy, anxiety and depression in de novo Parkinson's disease. Brain 2016;139(Pt 9):2486-2502.

83. Weintraub D, Koester J, Potenza MN, et al. Impulse control disorders in Parkinson disease: a cross-sectional study of 3090 patients. Arch Neurol 2010;67:589-595.

84. Steeves TD, Miyasaki J, Zurowski M, et al. Increased striatal dopamine release in Parkinsonian patients with pathological gambling: a [11C] raclopride PET study. Brain 2009;132(Pt 5):13761385 .

85. O'Sullivan SS, Wu K, Politis M, et al. Cue-induced striatal dopamine release in Parkinson's disease-associated impulsive-compulsive behaviours. Brain 2011;134(Pt 4):969-978.

86. Wu K, Politis M, O'Sullivan SS, et al. Single versus multiple impulse control disorders in Parkinson's disease: an (1)(1)Craclopride positron emission tomography study of reward cueevoked striatal dopamine release. J Neurol 2015;262:1504-1514.

87. Cilia R, Ko JH, Cho SS, et al. Reduced dopamine transporter density in the ventral striatum of patients with Parkinson's disease and pathological gambling. Neurobiol Dis 2010;39:98-104.

88. van Eimeren T, Pellecchia G, Cilia R, et al. Drug-induced deactivation of inhibitory networks predicts pathological gambling in PD. Neurology 2010;75:1711-1716.

89. Ray NJ, Miyasaki JM, Zurowski M, et al. Extrastriatal dopaminergic abnormalities of DA homeostasis in Parkinson's patients with medication-induced pathological gambling: A [11C] FLB457 and PET study. Neurobiol Dis 2012;48:519-525.

90. Joutsa J, Martikainen K, Niemelä S, Johansson J, Forsback S, Rinne JO, Kaasinen V. Increased medial orbitofrontal [18F]fluorodopa uptake in Parkinsonian impulse control disorders. Mov Disord 2012;27:778-782.

91. Ballanger B, van Eimeren T, Moro E, et al. Stimulation of the subthalamic nucleus and impulsivity: release your horses. Ann Neurol 2009;66:817-824.

92. Obeso I, Wilkinson L, Rodriguez-Oroz MC, Obeso JA, Jahanshahi M. Bilateral stimulation of the subthalamic nucleus has differential effects on reactive and proactive inhibition and conflict-induced slowing in Parkinson's disease. Exp Brain Res 2013;226:451-462.

93. Gee L, Smith H, De La Cruz P, et al. The influence of bilateral subthalamic nucleus deep brain stimulation on impulsivity and prepulse inhibition in Parkinson's disease patients. Stereotact Funct Neurosurg 2015;93:265-270.

94. Amami P, Dekker I, Piacentini S, et al. Impulse control behaviours in patients with Parkinson's disease after subthalamic deep brain stimulation: de novo cases and 3-year follow-up. J Neurol Neurosurg Psychiatry 2015;86:562-564.

95. Lim SY, O'Sullivan SS, Kotschet K, et al. Dopamine dysregulation syndrome, impulse control disorders and punding after deep brain stimulation surgery for Parkinson's disease. J Clin Neurosci 2009; $16: 1148-1152$.

96. Cho SS, Aminian K, Li C, Lang AE, Houle S, Strafella AP. Fatigue in Parkinson's disease: the contribution of cerebral metabolic changes. Hum Brain Mapp 2017;38:283-292.
97. Pavese N, Metta V, Bose SK, Chaudhuri KR, Brooks DJ. Fatigue in Parkinson's disease is linked to striatal and limbic serotonergic dysfunction. Brain 2010;133:3434-3443.

98. Bruns MB, Josephs KA. Neuropsychiatry of corticobasal degeneration and progressive supranuclear palsy. Int Rev Psychiatry 2013;25:197-209.

99. Cilia R, Rossi C, Frosini D, et al. Dopamine transporter SPECT imaging in corticobasal syndrome. PLoS One 2011;6:e18301.

100. Liscic RM, Srulijes K, Groger A, Maetzler W, Berg D. Differentiation of progressive supranuclear palsy: clinical, imaging and laboratory tools. Acta Neurol Scand 2013;127:362-370.

101. Masellis M, Momeni P, Meschino W, et al. Novel splicing mutation in the progranulin gene causing familial corticobasal syndrome. Brain 2006;129(Pt 11):3115-3123

102. Gabryelewicz T, Masellis M, Berdynski M, et al. Intra-familial clinical heterogeneity due to FTLD-U with TDP-43 proteinopathy caused by a novel deletion in progranulin gene (PGRN). J Alzheimers Dis 2010;22:1123-1133.

103. Eckert T, Tang C, Ma Y, et al. Abnormal metabolic networks in atypical parkinsonism. Mov Disord 2008;23:727-733.

104. Niethammer M, Tang CC, Feigin A, et al. A disease-specific metabolic brain network associated with corticobasal degeneration. Brain 2014;137:3036-3046.

105. Tang CC, Poston KL, Eckert T, et al. Differential diagnosis of parkinsonism: a metabolic imaging study using pattern analysis. Lancet Neurol 2010;9:149-158.

106. Tripathi M, Tang CC, Feigin A, et al. Automated differential diagnosis of early parkinsonism using metabolic brain networks: a validation study. J Nucl Med 2016;57:60-66.

107. Garraux G, Phillips C, Schrouff J, et al. Multiclass classification of FDG PET scans for the distinction between Parkinson's disease and atypical parkinsonian syndromes. Neuroimage Clin 2013;2: 883-893.

108. Mudali D, Teune LK, Renken RJ, Leenders KL, Roerdink JB. Classification of Parkinsonian syndromes from FDG-PET brain data using decision trees with SSM/PCA features. Comput Math Methods Med 2015;2015:136921.

109. Gerhard A, Trender-Gerhard I, Turkheimer F, Quinn NP, Bhatia $\mathrm{KP}$, Brooks DJ. In vivo imaging of microglial activation with $[11 \mathrm{C}](\mathrm{R})-\mathrm{PK} 11195 \mathrm{PET}$ in progressive supranuclear palsy. Mov Disord 2006;21:89-93.

110. Oh M, Kim JS, Kim JY, et al. Subregional patterns of preferential striatal dopamine transporter loss differ in Parkinson disease, progressive supranuclear palsy, and multiple-system atrophy. J Nucl Med 2012;53:399-406.

111. Xia CF, Arteaga J, Chen G, et al. [(18)F]T807, a novel tau positron emission tomography imaging agent for Alzheimer's disease. Alzheimers Dement 2013;9:666-676.

112. Shoup TM, Yokell DL, Rice PA, et al. A concise radiosynthesis of the tau radiopharmaceutical, [(18) F]T807. J Labelled Comp Radiopharm 2013;56:736-740.

113. Maruyama M, Shimada H, Suhara $T$, et al. Imaging of tau pathology in a tauopathy mouse model and in Alzheimer patients compared to normal controls. Neuron 2013;79:1094-1108.

114. Hammes J, Bischof GN, Giehl K, et al. Elevated in vivo [18F]AV-1451 uptake in a patient with progressive supranuclear palsy. Mov Disord 2016 Aug 1. doi: 10.1002/mds.26727. [Epub ahead of print]

115. Coakeley S, Cho S, Koshimori Y, et al. Positron emission tomography imaging of tau pathology in progressive supranuclear palsy. J Cereb Blood Flow Metab 2016. Submitted.

116. Lee SE, Rabinovici GD, Mayo MC, et al. Clinicopathological correlations in corticobasal degeneration. Ann Neurol 2011;70:327-340.

117. Respondek G, Stamelou M, Kurz C, et al. The phenotypic spectrum of progressive supranuclear palsy: a retrospective multicenter study of 100 definite cases. Mov Disord 2014;29:1758-1766. 